\title{
Implementing a flipped classroom approach in postgraduate education: An unexpected journey into pedagogical redesign
}

\author{
Christine Howitt and Mark Pegrum \\ The University of Western Australia
}

\begin{abstract}
This paper describes the implementation of a flipped approach by two lecturers teaching different postgraduate education courses at an Australian university. Case studies, written as chronological stories, were developed with data collected from email correspondence between the two lecturers as critical friends, as well as from student feedback in the form of face-to-face discussions, online discussions, emails, mind maps, multimodal discussion boards and end-of-semester university surveys. Over a period of 2 years, both lecturers moved from an initial focus on technology and organisation to a focus on pedagogy, while coming to see themselves as (re-)designers of learning. Technologically, the need for time to select and learn to work with appropriate software emerged as a key theme. Organisationally, the need for time to plan and to identify lecturer expectations of students emerged as key themes. Pedagogically, a shift occurred towards a listening pedagogy on the part of the lecturers, and towards more active and engaged learning on the part of the students. It was found necessary to ensure a close fit between what to present in flipped mode, what to do in class time, and how to assess students formatively and summatively.
\end{abstract}

\section{Introduction}

A new paradigm of customised instruction is emerging where educators aim to personalise student learning through relevance and flexibility (Keefe, 2007; Pegrum, 2014). This has resulted in the use of blended learning environments where traditional classroom interactions and e-learning and/or m-learning are utilised in various combinations, and where teachers increasingly become designers of learning (Laurillard, 2012; Mwanza-Simwami et al., 2011; Pegrum, 2014). One such instructional innovation is a flipped classroom approach where learners study online course materials before coming to class, so that class time is dedicated to discussion, assistance, or a range of activities to develop higher order thinking skills (Bergmann \& Sams, 2012; Davies, Dean, \& Ball, 2013). Significantly, both the 2014 and 2015 Higher Education Horizon Reports list flipped classrooms among their six key technological developments to watch, in both cases with a time-to-adoption horizon of one year or less (Johnson, Adams Becker, Estrada, \& Freeman, 2014, 2015).

Jonathan Bergmann and Aaron Sams, two high school chemistry teachers working at the time in Colorado, USA, are widely recognised as having developed today's concept of a flipped approach (Bergmann \& Sams, 2012; Milman, 2012; Tucker, 2012). While the phenomenon itself is not entirely new (Davies et al., 2013; McGivney-Burelle \& Xue, 2013; Tucker, 2012), the terminology is (though the term classroom flip appears to have been used earlier; see Missildine, Fountain, Summers, \& Gosselin, 2013), as are many of the readily available technologies now used to support it. This seems to be prompting many teachers to reflect on the organisation and pedagogy - in short, the design - of their classrooms. To date, however, there has been limited empirical research or academic publishing on flipped classrooms (Bergmann \& Sams, 2012; Davies et al., 2013; Milman, 2012), and even less on teachers’ perspectives on implementing a flipped approach.

\section{Literature Review}

\section{Nature of flipped classrooms}

In a flipped approach, information transmission occurs outside the classroom in the form of lectures generally delivered through videos (Bergmann \& Sams, 2012; EDUCAUSE, 2012) or alternative presentation formats such as slideshows, podcasts (O’Bannon, Lubke, Beard, \& Britt, 2011), and even readings. These materials may be accompanied by comprehension activities (EDUCAUSE, 2012) and/or behaviourist activities in the form of drills, exercises or puzzles. Classroom time is then used to build 
conceptual understanding and develop cognitive skills through active and collaborative learning (Baepler, Walker, \& Driessen, 2014).

There are two key advantages to a flipped approach. The first is that students have the flexibility to move at their own speed as they work through out-of-class elements, perhaps focusing on different videos or materials as appropriate to their levels and interests. This promotes student autonomy, and differentiation and personalisation of learning (Bergmann \& Sams, 2012; Davies et al., 2013; Gerstein, 2012). It may be of particular benefit to students with special needs or linguistic, social and other disadvantages (Bergmann \& Sams, 2012; EDUCAUSE, 2012; Thompson, 2011). Moreover, data generated on student actions and accomplishments may eventually feed into learning analytics (Enfield, 2013; Thompson, 2011).

The second advantage is that, with the more pedagogically traditional elements of education occurring outside the classroom, and students arriving in class primed for learning (Sams, 2013), in-class time is freed up for discussion, interaction, collaborative inquiry and hands-on activities (EDUCAUSE, 2012; Gerstein, 2012; Milman, 2012). Thus, with content transmission requiring lower-order skills having been removed from class time, higher-order skills can be engaged in class where students have teacher and peer support (McGivney-Burelle \& Xue, 2013). Such an approach sits comfortably with social constructivist learning theory (Vygotsky, 1978), where meaningful learning takes place when students interact with peers and teachers, actively engaging in the learning process in a collaborative environment. The teacher can also pay much more individualised attention to students, especially those who are struggling and need extra help (Rosenberg, 2013; Tucker, 2012). In other words, it is not the videos or other materials alone that are important, but how they support the overall learning design (Tucker, 2012).

As a means to describe the key components of a flipped approach, the Flipped Learning Network founded by Sams and Bergman, working in conjunction with Pearson and George Mason University, developed the F-L-I-P model (Hamdan, McKnight, McKnight, \& Arfstrom, 2013). The first pillar, flexible environments (F), refers to the variety of learning modes that can be utilised inside and outside the classroom, allowing students to learn in their own ways and at their own pace. The second pillar, learning culture (L), refers to the shift from a teacher-centred to a student-centred approach where learners are actively involved in knowledge formation. Intentional content (I) is the third pillar, referring to the teacher making decisions about the content to be delivered or explored outside the classroom and the activities to be engaged in inside the classroom. The fourth pillar, called professional educators (P), emphasises teachers' crucial role in orchestrating direct instruction, active learning, and student support and assessment. More recently, Chen, Wang, Kinshuk and Chen (2014) have appended P-E-D to the F-L-I-P model to make it more appropriate to a higher education context. Progressive networking activities $(\mathrm{P})$ refers to the active nature of a flipped approach, relating to Dewey's learning by doing and its contemporary realisation, learning by networking (i.e., through social media and online networking). Engaging and effective learning experience(s) (E) is an extension of the fourth pillar (P), professional educators, and relates to educators' need to "possess good instructional skills, strategies, and attitudes for promoting positive learning environments" (Chen et al., 2014; p. 19) and enhancing students' learning experiences. Diversified and seamless learning platforms (D) is an extension of the first pillar (F), flexible environments, and refers to digital platforms that provide "individualized, differentiated, personalized learning in a flexible, ubiquitous and seamless manner" (p. 20). With all seven pillars of the F-L-I-P-P-E-D model, the role of the teacher is paramount in implementing a flipped approach to make it successful for student learning. Chen et al. (p. 19) thus provide extra support for the idea, already embedded in the F-L-I-P model, that the role of educators is "even more crucial in flipped learning than in a traditional model”.

Recent variations on a flipped approach include students viewing videos or other materials as needed in class rather than outside it (e.g., Schwartz, 2013; Thompson, 2011), while in Bergmann and Sams' flipped mastery model (Bergmann \& Sams, 2012, 2013/2014; Sams, 2013), viewing videos is entirely optional, with students having the choice to learn in other ways if preferred. Indeed, it has been suggested there may be a natural progression beyond flipped classrooms to students finding and sharing their own learning resources within a problem-based or inquiry-based framework (Wright, 2012), which has even been described as Flipping 2.0 (Bretzmann, 2013). These developments arguably represent an extension of, rather than a fundamental change in, the flipped approach, placing further emphasis on students' active roles and teachers' designing roles. 


\section{Teacher and student roles in flipped classrooms}

To successfully implement a flipped model, teachers have to design, or redesign, the overall structure of learning - encompassing teacher and student roles - in light of their overarching pedagogical approach. Crucially, "out-of-class and in-class elements must be carefully integrated for students to understand the model and be motivated to prepare for class" (EDUCAUSE, 2012; p.2). Teachers face different challenges in developing out-of-class and in-class elements.

There are numerous issues to consider in the production of high-quality instructional videos or other presentation materials. There is always a danger of flipped videos being used to simply "perpetuat[e] bad teaching” (Schwartz, 2013; cf. Sams, 2013) in the form of lectures or drills (Thompson, 2011; Wright, 2012). One crucial video design element, widely remarked on in the literature, is conciseness. For example, Bergmann and Sams (2012) recommend that only one topic is covered per video, and that videos should be under 15 minutes, ideally under 10 minutes, and even as short as 5 minutes if possible. In the context of tertiary education, the EDUCAUSE 7 things you should know about flipped classrooms guide mentions videos of 5-7 minutes, while, in the more specific context of tertiary chemistry, Bridgeman (2013) suggests that 3-5 minutes is adequate. The succinctness of a video will depend on various factors, including content and level, but the core message is: make it short. This ensures materials are as granular as possible, and promotes re-watching (Rosenberg, 2013).

Beyond this, there is much for teachers to learn about an area which is often only anecdotally addressed in the flipped literature, namely the optimal design of multimodal instruction. The key elements are perhaps best described in Mayer's (2009) cognitive theory of multimedia learning, which provides clear, empirically supported guidelines on multimodal instruction, including for instance the need to delete extraneous material; signal key material; delete redundant captions; present material in user-paced segments; pre-teach key elements; accompany pictures with spoken rather than written text; use words and pictures rather than just words; and adopt a personalised style (Pegrum, 2014). There is little doubt that pre-recording video lectures or preparing other flipped materials, especially concise, multimodally optimised materials, is extremely time consuming (Bergmann \& Sams, 2012; Enfield, 2013; McGivney-Burelle \& Xue, 2013). Naturally, designing appropriate accompanying quiz questions, especially if they are intended to lead into class activities, represents a further time commitment.

It is just as important for teachers to consider what should happen in class time as what should happen out of class time (Enfield, 2013). As Gerstein (2012) points out: "Educators need to be re-educated as to what to do with the class time that previously was used for their lectures" (Kindle location 100); she goes on: "The educator becomes a facilitator and tour guide of learning possibilities - offering these possibilities to the learners and then getting out of the way” (Kindle locations 206-207). Numerous accounts of flipped classrooms devote considerable attention to explaining how, in line with progressive pedagogical approaches like social constructivism, teachers can and should become facilitators of active, personalised, student-centred learning in the time which has been freed up in their face-to-face classes (e.g., Bergmann \& Sams, 2012; Bretzmann, 2013; McGivney-Burelle \& Xue, 2013).

Students also have a role to play in the success of a flipped classroom approach. Naturally, they need adequate hardware, software and connectivity to watch videos (Milman, 2013; Rosenberg, 2013; Sams, 2013). Some learner training on the rationale for a flipped classroom is likely to be necessary, especially as students are required to take greater responsibility for their learning (Davies et al., 2013; EDUCAUSE, 2012). Learners may well need guidelines on how to view videos or other materials effectively; Bergmann and Sams (2012) recommend that teachers should ask students to turn off other media channels; "liberally use the pause button” (p.14); take notes; and ask rich and interesting questions. Of course, even with learner training, there is no guarantee that all students will watch the videos or work through the materials provided (Milman, 2013), though the same is true of any materials students are asked to work through in preparation for a class (Rosenberg, 2013). Moreover, Rosenberg indicates that there may be insufficient scaffolding for some students, who are usually unable to pose questions immediately to the teacher or their peers. In brief, there is a lack of a direct feedback loop where teachers can question students to check understanding, and students can question teachers to improve understanding. 


\section{Flipped classrooms in practice}

A number of studies across a range of disciplines at tertiary institutions have shown promising results with the use of a flipped approach. In some cases it has been found to produce improved learning outcomes (e.g., McGivney-Burelle \& Xue, 2013; Missildine et al., 2013; Pierce, 2013), and in many cases it has led to greater student satisfaction (e.g., Enfield, 2013; McGivney-Burelle \& Xue, 2013; Pierce, 2013). It has been suggested that students' increased ownership of self-paced work, including note-taking from videos and responding to questions, can contribute to learning outside class (Davies et al., 2013; Enfield, 2013). Inside class, learning may be improved through a greater emphasis on active learning, including problem solving, as well as teachers' ability to focus on students who need extra help (Davies et al., 2013; McGivney-Burelle \& Xue, 2013). Moreover, Enfield (2013) has found an improvement in students' self-efficacy in regard to independent learning through participation in a flipped approach, and considers that such an approach may help prepare students for twenty-first century careers. However, some caution is necessary; Strayer (2012) found that students struggled to connect online and face-to-face course components and to orient themselves to classroom tasks, while Missildine et al. (2013) found that students were more satisfied with traditional lecture and lecture capture approaches, reporting that the flipped approach required more work, and failing to appreciate the value of interactive learning.

Most empirical studies of perceptions of a flipped approach focus on student rather than teacher views, notwithstanding the many anecdotal accounts by educators describing their flipped classrooms (e.g., Enfield, 2013; McGivney-Burelle \& Xue, 2013). Given the importance that Chen et al. (2014) and others place on the role of the teacher in implementing a flipped approach, it is timely that research is conducted from teachers' perspectives. The current study describes educators' perspectives on the implementation of a flipped approach in two different postgraduate education courses, asking the following questions:

- What are educators' perspectives on the processes and issues associated with implementing a flipped classroom approach?

- What common themes emerge from implementing a flipped approach in two very different classes?

\section{Methodology}

This research employs a qualitative case study design. Case study research is interpretive as it attempts to bring to life and recreate the lived experiences of participants by describing and interpreting phenomena in the context of particular settings (Merriam, 1998). Case studies are particularly appropriate to education as they assist in understanding a process or problem with a view to improving practice. Descriptive case studies can provide detailed accounts of phenomena where little research has been conducted to date (Merriam, 1998), as is the situation with research into educators' perspectives on implementing a flipped approach. The authors do not claim that these are expert case studies. Rather, we aim to highlight our ideas, successes and failures in implementing a flipped approach so that our experiences may inform the practices of others.

The authors of this paper are two university lecturers working in the same faculty of education at an Australian university. We had each decided, independently, to implement a flipped approach in one of our classes in 2012. While these classes were taught in very different ways, we thought it would be valuable to support each other through email correspondence as critical friends who could provide supportive critique, taking on a consultative and evaluative role (Costa \& Kallick, 1993). Within education, "critical friends are valuable change agents who make the work of reflexive practice more collaborative” (Schneider \& Parker, 2013; p. 1). Our correspondence continued from 2012-2013, covering two iterations of each of our courses, and provides a record of changes in our thinking and practices over this period.

Data were collected through the abovementioned email correspondence between the authors as critical friends, as well as through student feedback. Emails were usually sent at least weekly, as we described our own exploration of a flipped approach, offered feedback and suggestions to each other, and deepened our understanding by comparing our experiences. Interestingly, two-thirds of our correspondence, by volume, took place in the first year, 2012. We corresponded less often, and more succinctly, as our approaches became better established in 2013. Our correspondence sometimes included, and our data have generally 
been supplemented by, student feedback. This came from a number of sources: students' comments on our respective implementations of a flipped approach (drawn from face-to-face discussions in class, online discussions, and emails); students' work which made reference to the flipped approach (ranging from mind maps created by Christine's students to multimodal discussion boards used by Mark's students); and students' anonymous comments on standardised university surveys carried out at the end of each semester.

Working independently, we each wrote our case study as a chronological narrative, or story. Stories have been used extensively in educational and other social research as they are considered "the fundamental unit that accounts for human experience” (Pinnegar \& Daynes, 2007; p. 4). We chose this story approach as it allowed us to tell our lived experience and describe our developing knowledge and understanding in our own words, as recommended by Pinnegar and Daynes. By reviewing our email correspondence we could identify important events throughout each year and reflect on how we had changed our practices across the 2 years as we became more familiar with a flipped approach. Student feedback was added to our stories to support our assertions and highlight key points. We then read each other's case study with a critical eye, looking for internal consistency and the use of appropriate evidence, and posing questions to be addressed in a revised version. Through this process we became immersed in the two stories, and were subsequently able to employ content analysis to identify similarities and differences (Merriam, 1998). Three major common themes emerged, namely, the need to deal with technical, organisational and pedagogical issues in implementing a flipped approach. The two stories were then independently edited in line with these themes and critically reviewed again, a process which was repeated several times, with the themes gradually becoming more clearly established and the associated revisions becoming more minor. The use of cycles of construction, reflection and analysis added to the rigour of the research, increased the authenticity of the case studies, and provided us with an opportunity for increased reflection on our practice (Wallace \& Louden, 2000).

In line with institutional ethics requirements, students gave consent for collection and analysis of their data, were informed they could withdraw from the research at any time, and were assured of confidentiality and anonymity.

\section{Findings}

The two cases are presented in terms of context and process, and have been written in the first person to reflect our own experiences. They outline our emerging ideas, successes and failures, and are based around the three major themes that arose during our implementation of a flipped approach: the need to work through technical, organisational and pedagogical issues.

\section{Christine's story}

I teach a small group of early childhood students about effective learning environments in the second semester of a four semester initial teacher education program, in which all students are loaned an iPad for their first year. As this course had only been taught for 1 year, it was effectively designed in flipped mode from the ground up. Four of the 10 weeks of semester had previously been spent outside the university to explore and reflect on a range of indoor and outdoor environments for effective learning. Even though the 3 hour face-to-face workshop sessions were practically based, I was still concerned that too much time was spent on lectures before moving on to the practical components. I have always believed in active learning and social constructivism, but found myself questioning my own pedagogy on how to make this happen in a more meaningful manner for myself and the students. So when the idea of using a flipped classroom was mooted due to my involvement in other technology-based education projects, I eagerly accepted the opportunity.

In developing and implementing a flipped approach I found myself referring to the trichotomous relationship between content, practice and assessment. Content was delivered online through the university's learning management system, Moodle, in the form of PowerPoint presentations that students worked through prior to workshops. Practice took place in workshop sessions where students applied the content through appropriate activities and discussions. A backward planning approach was taken, where both content and practice related directly to student assessment.

All 10 weeks of the semester were delivered using a flipped approach. Students were advised (by email and verbally) before the start of the semester that this approach would be used, and told to follow the instructions 
in the PowerPoint for the first week. A short overview of the flipped approach was provided online and it was also explained at the start of the first workshop. In 2012, the class consisted of 12 students from four countries, with 6 of 10 workshops held off campus. In 2013, the class consisted of 15 students representing eight countries, with 7 of the 10 workshops delivered off campus.

In the first year of implementation I found the major issue was organisational, and centred on time for decisions and for development. Firstly, considerable time was required to conceptualise what a flipped classroom approach would look like. Secondly, further time was required to develop the content and structure of the PowerPoint presentations, which was linked to technological issues. I finally settled on using PowerPoints that summarised major conceptual points, linked to readings, videos or e-learning tools (such as Padlet, Wordle or mind mapping apps on the iPad). For someone with limited experience of technology, the choice of e-learning tools also required time. In retrospect, I found I had intuitively implemented some of Mayer's (2009) multimodal instruction principles in developing the PowerPoints: clear goals, information in small and coherent segments, and slides presented as words and pictures. I chose not to include any videos of myself presenting lectures; rather, I utilised a range of relevant online videos. I felt that online lectures by me reverted back to the transmissive style of teaching that I was trying to avoid. All videos were less than 10 minutes' duration.

Thirdly, still more time was required to develop the activities and sequencing of the workshops. I needed to think through the provision of appropriate authentic activities to reinforce the key concepts, relate to the off campus context, and connect with the assessment. In this process I became more aware of the importance of clearly defined learning objectives. I found the material for the first 3 weeks took a long time to develop, and I questioned myself many times on why I was doing this. Thankfully, my perseverance saw positive results, which reinforced my belief in this approach.

All workshops started with a short revision of the main concepts presented in the week's PowerPoint, and then moved on to an application of these concepts. The following email correspondence highlights the success of this process:

It worked! It worked! It has taken until Week 4 to sort it all out but it finally worked this week! We are still based at School A. We started with revision of the seven principles of materials, where the students had to describe what each of the principles meant. This generated some excellent discussion amongst the students and me. The students then had to pick one of the seven characteristics and go into a classroom and take a photograph to illustrate the principle. Not only was this a means of checking their understanding of the principles, but it also related directly to their first assignment. They then came back and shared their photographs and explanations with the whole class. Everyone had to contribute here. The format - summarise the PowerPoint, apply the principles, and then share the findings - worked really well in this context. It immediately takes theory and turns it into practice. And the theory has been covered before coming to class. (Christine, critical email correspondence, 14 August 2012)

A further component of organisational issues related to my expectations of the students. I was initially unsure whether the students would understand their role in this approach and be prepared to fulfil it, as the whole structure collapses if they do not prepare before coming to the workshops. As the weeks progressed my uncertainty shifted to assumptions, thus setting high expectations of the students. I was comfortable with this as it reinforced various university graduate attributes, such as students becoming independent learners.

I make the assumption the students have read the PowerPoint and done the readings. Or perhaps I should say that I expect them to have done this. ... It really does shift the emphasis off me trying to impart the knowledge through lectures, to them putting in the yards and trying to grasp the concepts and then coming to class with questions. (Christine, critical email correspondence, 11 August 2012)

Overall, students' perceptions of the flipped approach, as indicated through group mind maps and end-ofsemester surveys, were positive. They identified various affordances of this approach relating to time and autonomy. Time related to: more time to think about their own perspectives and generate specific questions 
beforehand, more time for questioning in class, and more time for hands-on learning in different contexts. Autonomy related to: more enthusiasm for the topic as students knew the material and the direction the workshop would head in, and richer class discussion through greater sharing of ideas and opinions. Limitations the students identified related to technology failing, inequality in workshop participation if some students had not completed the required work, and the time needed to prepare for the workshops.

Having dealt with many of the organisational issues in the previous year, the main issues during 2013 became pedagogical as I sought to prioritise student engagement for learning. I aimed to establish a more student-centred learning environment in the workshops, based on collaborative learning and giving students more voice. Spending more time off campus required additional thought on how to utilise and facilitate collaborative learning.

On an organisational note, I refined the activities leading into the assessment so they became more streamlined. This aspect of the flipped approach worked extremely well and many times I made comments in the critical email correspondence along these lines: "if I had to teach the theory in this face-to-face session, there is no way that the students could work towards their assignments. So the advantage of the flipped model in assisting with assignments has really stood out this year” (31 July 2013).

Once again, my expectations of the students played a role, but this time the expectations were clearly delivered at the start: there would be no face-to-face lectures, students would be expected to come to class prepared, student discussions would form a large part of their learning, and all were expected to participate. Additionally, I set a 'minimum expectation' for each PowerPoint to ensure that all students were prepared for the workshop; for example, watching a video and making notes to bring along for discussion.

The biggest issue I faced in 2013 was the students themselves, due to the large number of international students accustomed to a more transmissive teaching style. Not only were these students learning how to be teachers, they were also learning how to learn. Even though the concept had been covered in the previous semester, there was limited understanding of social constructivism. Consequently, the ideas of shared understanding, learning from fellow students, and learning at any time and in any place, represented a huge shift in thinking which only a few of the international students managed to appreciate by the end of the semester. As Missildine et al. (2013) noted, some students fail to appreciate the value of interactive learning.

Overall, the feedback was again positive, with students identifying similar affordances and limitations as in the first year of implementation. However, this cohort placed more emphasis on their active roles in their own learning, commenting in the group mind maps that: "You have more opportunity to share and listen to different perspectives" and: "If you disagree with a particular point, you can raise it in the lesson". Further, this cohort also commented in a mind map on my expectations: "More opportunities for students to speak up. Christine expects us all to contribute”.

These last two years have seen me move from an enthusiastic explorer of a flipped approach to a proactive advocate. After initially stating that I could not see how to use this approach in other courses, I now actively look for ways to embed it. I have renewed enthusiasm for the close relationship between teaching, learning and assessment, and look for new ways to bring these elements closer together in other courses.

\section{Mark's story}

I've been teaching my 10 week e-learning course within a Master's program for practising educators since 2007. It incorporates weekly 2 hour face-to-face tutorials where a considerable amount of continually updated content relating to key themes and key technologies is presented and discussed; optional weekly labs in which participants receive guidance as they explore new technologies in a hands-on way and conceptualise their course projects; and a class wiki, where participants discuss course topics and comment on each other's developing projects.

I'd long felt that the need to cover a large amount of new content, including foundational as well as more cutting-edge material, was turning my tutorials into jam-packed information delivery sessions, with the more constructivist elements of the learning process largely relegated to the labs and the wiki. In 2012, in a class of 15 students from seven countries, I decided to replace all my tutorial presentations with flipped videos. Although the material for each tutorial was chunked into four to six videos, these often added up to 
more than an hour in total; in essence, I just put my tutorial presentations online in a slightly more concise format than in the face-to-face tutorials themselves. However, some non-core material was also included in the form of invitations to pause the videos and consult a variety of relevant online materials.

Unfortunately, a number of intertwined technological, organisational and pedagogical issues, and the time drain they represented, almost undermined the project from the outset. Initially, technological issues loomed large. It was only after a time consuming process of experimenting with different software that I settled on the combination of Echo 360 video capture software and PowerPoint presentations with voiceovers (later replaced for simplicity's sake with videos generated directly from PowerPoint), which met my needs and felt comfortable to use. Connectivity was an issue when it came to uploading videos, and for some students when it came to viewing them, meaning that both of these needed to be done on campus. Organisational issues also demanded time. It took two full days to get four initial videos (replacing one tutorial presentation) finished, uploaded, and linked into my course outline on Moodle. I soon learned not to try for the perfect lecture, something that gradually became easier with time. Although, generally speaking, it was demanding to be so well-organised so far ahead of time, it did make preparation for tutorials easier, and it saved time when students missed class or arrived late, as I could direct them to the flipped videos.

It was only once the technological and organisational issues were satisfactorily dealt with that I could consider the pedagogical issues in more detail - and realised I had failed to capitalise on the opportunity (and, arguably, the requirement) for pedagogical redesign. I found myself questioning what to present in flipped mode, what to do in class, and how to link the two.

While participants indicated in tutorial discussions that they generally found the length of the individual videos suitable, they sometimes struggled to watch them all. Most liked having the option to pause the videos and view other materials, with one typical wiki comment reading: "an additional benefit is that midway through the 'lectures' the reader is free to 'leave' to explore related links before coming back to the video". This higher level of autonomy appeared to particularly benefit the numerous non-native speakers in the class, as well as those who were very unfamiliar with the technological subject matter. However, I felt the degree of autonomy the students were experiencing fell far short of what was possible.

Repetition between out-of-class and in-class content became an issue. I was aware that a few students had not watched the videos, and it was easy to slip back into a more transmissive mode involving too much recapitulation, with basic questions from those who hadn't seen the videos sometimes undermining potentially richer discussions. However, there was more time for conversation and questions than previously, and I was able to elicit some sophisticated commentary from students. Over time, I realised that the class wiki had also begun to serve as a platform for a feedback loop between the videos, the students, and myself. Yet I still felt both our class wiki and our class time could be better exploited if they were better integrated with the flipped materials.

Despite these issues, participants praised the flipped approach in end-of-semester surveys. One enthusiast wrote: "LOVE LOVE LOVE the flipped classroom model. It keeps the classroom for real learning”. Since my students are also teachers, it was interesting to observe that in their final assessed projects, where they had a free hand to design whatever technologically informed innovations they thought most appropriate to their own classrooms, 5 out of 15 chose to implement some kind of flipped approach.

Ultimately, I concluded that retrofitting an existing course in flipped mode is less effective than designing a course in flipped mode from the ground up. I determined, nevertheless, to make far greater structural changes the following year. Like Christine, I found that instead of starting off 2013 focusing on technological and organisational issues, I was ready to begin with a process of pedagogical redesign. In my 2013 class, consisting of 23 students from six countries, I reinstated tutorial presentations on key themes and only replaced every second presentation, namely those focusing on specific technological tools, with flipped videos. Borrowing a term from Christine, I set a minimum expectation for students to watch one video per flipped session. This was not only to make the viewing component more manageable, but to allow students to take more responsibility for focusing on those aspects of the course which were of most interest and relevance to them. Additionally, I set a post-video task where students answered specific questions about their chosen tools on the class wiki, demonstrating their understanding in what was effectively a kind of formative assessment, while also responding to their classmates' comments on other tools. I collected a selection of these comments during the week and, in the following face-to-face tutorial, projected them in 
a slideshow. Students who had watched and commented on a given video were asked to lead the class discussion on the tool in question.

Technological and organisational issues were much less prominent in 2013. While I found I had intuitively implemented some of Mayer's (2009) multimodal instruction principles the previous year, I sought to work with them in a more considered way in 2013. I reduced presentation material to its bare essentials, and made greater use of invitations to viewers to pause the videos and explore other materials. As a result, the 2013 videos were on the whole several minutes shorter than the corresponding 2012 videos. A key aspect of my pedagogical redesign, then, involved me finding ways to talk less, something that carried over into the follow-up wiki discussions as well as the face-to-face tutorials, both of which were very much led by students.

The inclusion of a post-video wiki task created a clear feedback loop, and began the process of students learning from each other; as one participant commented on the wiki: "I am learning a lot from following everyone's reflection pages especially when there are links to follow”. It also allowed me to distil students' wiki discussions into a list of key points to initiate our face-to-face discussions, reflecting students' ideas back to them with names attached (see Figure 1). While no penalties were imposed if an individual had not contributed to the wiki discussion, this follow-up process made it obvious who had contributed, and the experience of seeing their comments presented on the screen and being asked to lead a discussion was perhaps sufficiently empowering that nearly all students did contribute every fortnight. Those who had not watched a particular video were obliged to direct their questions to other students, rather than to me.

\section{Thinking about social bookmarking (folksonomies) ...}
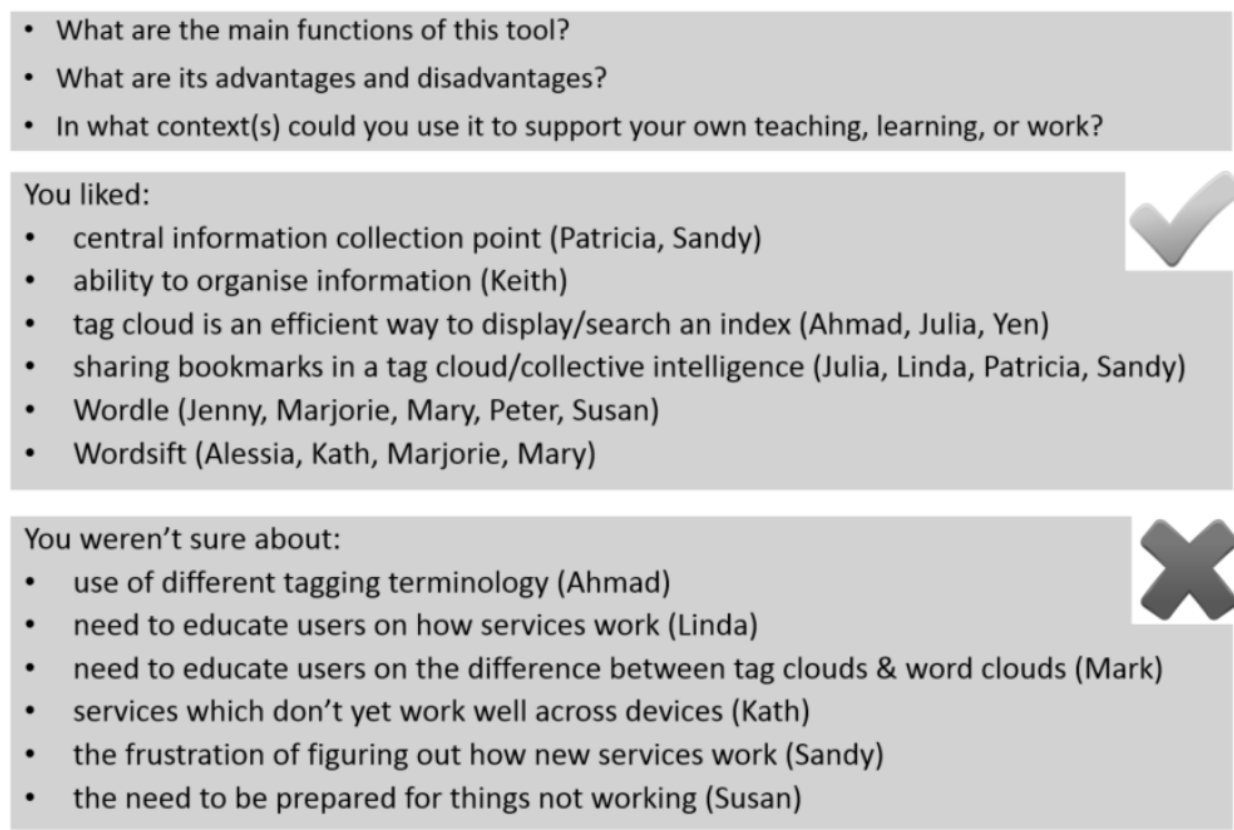

Figure 1. A 2013 PowerPoint slide reflecting students' comments back to them (names have been changed) \& incorporating one additional comment of my own (my name remains unchanged).

Feedback was even more positive in 2013, with participants particularly valuing the time to "think through how [they] might actually use various technological tools before coming to class", as one put it in end-ofsemester feedback, so that they were ready to engage in a rich discussion in class time. Five of the 23 participants chose to implement a flipped approach in their course projects, with a sixth doing so implicitly, and four others using the idea of a flipped approach to inform their overall thinking about teaching (e.g., asking their own students to prepare more at home before class).

In summary, though I was still retrofitting my course in 2013, I engaged in a more sweeping redesign, focusing more on pedagogy than technology or organisation. My classes became more oriented towards 
students' co-construction of understanding as I realised that, having set up the appropriate learning structures, I could - and should! - take a back seat in the discussions themselves. In other versions of this course which are delivered in compressed mode, I have modified my pedagogy still further to allow students a choice of watching videos in class time or beforehand, or consulting alternative materials instead of the supplied videos, thus moving in the direction of Bretzmann’s (2013) Flipping 2.0.

\section{Discussion and Conclusion}

This research sought to determine two educators' perspectives on the processes and issues associated with implementing a flipped classroom approach in two different postgraduate education courses across a twoyear period, using a story-based case study approach anchored in email correspondence between critical friends. Organisational and technological issues dominated the first year of implementation, the former connected with planning time and identifying lecturer expectations of students, and the latter with selecting and building familiarity with appropriate software. Only in the second year of implementation, when sufficient time could be devoted to pedagogical (re-)design, were the real benefits of a flipped approach realised. This highlights the importance of both time (including enough time to revise the strategies employed) and flexibility in implementing a flipped approach.

Pedagogically, a shift occurred towards more student-centred learning in both Christine and Mark’s classes through the development of a listening pedagogy, a term taken from early childhood education. A listening pedagogy recognises students as "active and powerful agents in their own learning and development" (Egan, 2009; p. 45) and stresses the role of dialogic practice in the development of understanding. Christine referred to "giving students more voice", while Mark mentioned "finding ways to talk less" - not unlike Gerstein (2012), who spoke of "getting out of the way”. These expressions all refer to a similar pedagogical shift, where teachers, while facing a more taxing role as designers, are less dominant in class interactions, and where students take a more active role in their own learning, which they can shape in individualised ways. The process of implementing a flipped approach, and the pressure it brings for pedagogical redesign, seems to encourage educators to re-evaluate the structures of learning they set up for their students, and what it means to teach within those structures. In some contexts, it may be possible to give students even more autonomy to choose their own learning materials and work at their own pace. Ultimately, flipped classrooms are less about the technological and organisational elements, and more about new forms of technology and new approaches to organisation facilitating changes in pedagogy.

Ensuring a close fit between what to present in flipped mode, what to do in class time, and how to assess students formatively and summatively, was evident in both Christine and Mark's stories. The three-way relationship between content, practice and assessment was a prominent element of Christine's redesign. She utilised a backward planning process and careful design of programme elements to ensure the link between these three aspects. Mark found himself placing more emphasis on formative assessment, but noted that the flipped approach also fed into summative assessments, with many teachers who participated in his courses seizing the chance to implement such an approach in their course projects. There is little mention in the literature of the place of assessment when implementing a flipped approach, but it should be considered from the outset so that in-class and out-of-class activities better align with assessment requirements.

The learners in our study found that a flipped approach resulted in more autonomy coupled with the need to take more responsibility, which echoes findings in other research (Davies et al., 2013; Enfield, 2013; Gerstein, 2012). Associated with this was a heavier demand on students in terms of time and possibly overall workload. Although the literature has much to say about demands on teachers' time, it is mostly silent about demands on students' time, with a few exceptions such as Missildine et al. (2013), who noted students' view that a flipped approach entails more work. Certainly, both Christine and Mark found the demands on student time to be a key practical consideration. The use of minimum expectations in out-ofclass work should be considered as a means to reduce student workload.

In different contexts, a flipped approach can look very different in terms of the technologies employed, and in terms of the exact relationship between out-of-class, in-class and assessable elements, but it is always fundamentally about shifting from teacher-centred to student-centred structures of learning. Although flipped materials can promote student autonomy and learning differentiation, it is the overall flipped structure that is potentially most transformative, because of the way it frees up classroom time for 
interaction, collaboration, and co-construction of understanding - which, if well-structured by teachers as part of their pedagogical redesign, can be very much dominated by students and their evolving needs and interests.

This research was limited because it was conducted with postgraduate students, who are often more motivated and committed than undergraduate students, and in small-sized classes, where more personal interaction is possible. Compared to other disciplines, students of education are likely to be more open to exploring alternative teaching and learning strategies, and possess the metalanguage to conceptualise and discuss a flipped approach. There is a need for complementary research on teacher and student perspectives to be carried out at undergraduate level, in larger classes, and with students from outside the discipline of education.

\section{References}

Baepler, P., Walker, J. D., \& Driessen, M. (2014). It’s not about seat time: Blending, flipping, and efficiency in active learning classrooms. Computers \& Education, 78, 227-236.

Bergmann, J., \& Sams, A. (2012). Flip your classroom: Reach every student in every class every day. Eugene, OR: ISTE.

Bergmann, J., \& Sams, A. (2013/2014). Flipping for mastery. Educational Leadership, 71(4), 24-29.

Bretzmann, J. (Ed.). (2013). Flipping 2.0: Practical strategies for flipping your class. New Berlin, WI: The Bretzmann Group.

Bridgeman, A. J. (2013). Active learning online and in class: Guided inquiry in first year chemistry. Paper presented at the Sydney Teaching Colloquium, The University of Sydney. Retrieved from https://dl.dropboxusercontent.com/u/29569221/STC_AJB.pptx

Chen, Y., Wang, Y., Kinshuk, \& Chen, N.-S. (2014). Is FLIP enough? Or should we use the FLIPPED model instead? Computers \& Education, 79, 16-27.

Costa, A. L., \& Kallick, B. (1993). Through the lens of a critical friend. Educational Leadership, 51(2), 49-51.

Davies, R. S., Dean, D. L., \& Ball, N. (2013). Flipping the classroom and instructional technology integration in a college-level information systems spreadsheet course. Educational Technology Research \& Development, 61(4), 563-580. doi.org/10.1007/s11423-013-9305-6

EDUCAUSE. (2012). 7 things you should know about flipped classrooms. EDUCAUSE. Retrieved from http://www.educause.edu/library/resources/7-things-you-should-know-about-flipped-classrooms

Egan, B. A. (2009). Learning conversations and listening pedagogy: The relationship in student teachers' developing professional identities. European Early Childhood Education Research Journal, 17(1), 4356. doi.org/10.1080/13502930802689012

Enfield, J. (2013). Looking at the impact of the flipped classroom model of instruction on undergraduate multimedia students at CSUN. TechTrends, 57(6), 14-27. http://dx.doi.org/10.1007/s11528-013-06981

Gerstein, J. (2012). The flipped classroom: The full picture. Amazon Digital Services.

Hamdan, N., McKnight, P., McKnight, K., \& Arfstrom, K. M. (2013). The flipped learning model: A white paper based on the literature review titled A Review of Flipped Learning. Flipped Learning Network. Retrieved from http://researchnetwork.pearson.com/wpcontent/uploads/WhitePaper_FlippedLearning.pdf

Johnson, L., Adams Becker, S., Estrada, V., \& Freeman, A. (2014). NMC Horizon Report: 2014 Higher Education Edition. Austin, TX: The New Media Consortium. Retrieved from http://www.nmc.org/pdf/2014-nmc-horizon-report-he-EN.pdf

Johnson, L., Adams Becker, S., Estrada, V., \& Freeman, A. (2015). NMC Horizon Report: 2015 Higher Education Edition. Austin, TX: The New Media Consortium. Retrieved from http://cdn.nmc.org/media/2015-nmc-horizon-report-HE-EN.pdf

Keefe, J. W. (2007). What is personalization? Phi Delta Kappan, 89(3), 217-223. doi.org/10.1177/003172170708900312

Laurillard, D. (2012). Teaching as a design science: Building pedagogical patterns for learning and technology. New York, NY: Routledge.

Mayer, R. E. (2009). Multimedia learning (2nd ed.). New York, NY: Cambridge University Press.

McGivney-Burelle, J., \& Xue, F. (2013). Flipping calculus. PRIMUS, 23(5), 477-486. doi.org/10.1080/10511970.2012.757571 
Merriam, S. B. (1998). Qualitative research and case study applications in education. San Francisco, CA: Jossey-Bass.

Milman, N. B. (2012). The flipped classroom strategy: What is it and how can it best be used? Distance Learning, 9(3), 85-87.

Missildine, K., Fountain, R., Summers, L., \& Gosselin, K. (2013). Flipping the classroom to improve student performance and satisfaction. Journal of Nursing Education, 52(10), 597-599. doi.org/10.3928/01484834-20130919-03

Mwanza-Simwami, D., Kukulska-Hulme, A., Clough, G., Whitelock, D., Ferguson, R., \& Sharples, M. (2011). Methods and models of next generation technology enhanced learning. White paper. Alpine Rendezvous, March 28-29, La Clusaz, France. Retrieved from http://oro.open.ac.uk/29056/1/Methods_and_models_of_next_generation_TEL.pdf

O’Bannon, B. W., Lubke, J. K., Beard, J. L., \& Britt, V. G. (2011). Using podcasts to replace lecture: Effects on student achievement. Computers \& Education, 57, 1885-1892.

Pegrum, M. (2014). Mobile learning: Languages, literacies and cultures. Basingstoke, Hampshire: Palgrave Macmillan.

Pierce, R. (2013). Student performance in a flipped class module. In R. McBride, \& M. Searson (Eds.), Proceedings of Society for Information Technology \& Teacher Education International Conference 2013 (pp. 942-954). Chesapeake, VA: AACE. Retrieved from http://www.editlib.org/p/48235

Pinnegar, S., \& Daynes, J. G. (2007). Locating narrative inquiry historically: Thematics in the turn to narrative. In J. Clandinin (Ed.), Handbook of narrative inquiry: Mapping a methodology (pp. 3-34). Thousand Oaks, CA: Sage.

Rosenberg, T. (2013, October 9). Turning education upside down. The New York Times. Retrieved from http://opinionator.blogs.nytimes.com/2013/10/09/turning-education-upside-down/

Sams, A. J. (2013). Flipped classroom meets mobile learning. In Z. L. Berge, \& L. Y. Muilenburg (Eds.), Handbook of mobile learning (pp. 259-267). New York, NY: Routledge.

Schneider, J., \& Parker, A. (2013). Conversations in a pub: Positioning the critical friend as "peer relief" in the supervision of a teacher educator study abroad experience. The Qualitative Report, 18(16), 114. Retrieved from http://www.nova.edu/ssss/QR/QR18/schneider32.pdf

Schwartz, K. (2013, May 21). Flipped classroom 2.0: Competency learning with videos. Mind/Shift. Retrieved from http://blogs.kqed.org/mindshift/2013/05/flipped-classroom-2-0-masterylevelcomptenecy-learning-with-videos/

Strayer, J. F. (2012). How learning in an inverted classroom influences cooperation, innovation and task orientation. Learning Environments Research, 15(2), 171-193. doi.org/10.1007/s10984-012-9108-4

Thompson, C. (2011). How Khan Academy is changing the rules of education. Wired, 19(8). Retrieved from http://www.wired.com/magazine/2011/07/ff_khan/

Tucker, B. (2012). The flipped classroom. Online instruction at home frees class time for learning. Education Next, 12(1), 82-83. Retrieved from http://educationnext.org/the-flipped-classroom/

Vygotsky, L. (1978). Mind in society: The development of higher psychological processes. Cambridge, MA: Harvard University Press.

Wallace, J., \& Louden, W. (2000). Teachers' learning: Stories of science education. Dordrecht: Kluwer Academic Publishers.

Wright, S. (2012, October 8). The flip: End of a love affair. Powerful Learning Practice. Retrieved from http://plpnetwork.com/2012/10/08/flip-love-affair/

Corresponding author: Christine Howitt, christine.howitt@uwa.edu.au

Australasian Journal of Educational Technology (C) 2015.

Please cite as: Howitt, C. and Pegrum, M. (2015). Implementing a flipped classroom approach in postgraduate education: An unexpected journey into pedagogical redesign. Australasian Journal of Educational Technology, 31(4), 458-469. 